Pak. j. sci. ind. res. Ser. A: phys. sci. 201457 (3) 176-179

\title{
Unbodied Dehydrated Castor Oil from Oil of Castor Beans Cultivated in Tropical and Sub Tropical Zones of Pakistan
}

\author{
Rubina Saleem*, Razia Sultana, Ambrat and Aftab Ahmad Kandhro \\ Applied Chemistry Reasearch Centre,PCSIR Laboratotries Complex, Karachi \\ Shahrah-e-Dr. Salimuzzaman Siddiqui, Karachi-75280, Pakistan
}

(received March 11, 2013; revised November 18, 2013; accepted November 21, 2013)

\begin{abstract}
Commerciallyavailable castor oil was analysed for specific gravity at $25 / 25^{\circ} \mathrm{C}(0.959)$, acid value $(0.5)$, iodine value (85), refractive index at $25^{\circ} \mathrm{C}(1.4769)$, viscosity at $25^{\circ} \mathrm{C}(6.8)$, and hydroxyl value (162). Fatty acid composition, including palmitic acid (1.7\%), stearic acid (1.39\%), oleic acid (5.73\%), linoleic acid (6.25\%), and ricinoleic acid (84.2\%) was estimated by means of GLC. Unbodied dehydrated castor oil (DCO- 15) 93\% was prepared by using sodium bisulphate and sodium bisulphite and other reaction conditions. Unbodied DCO was analysed for iodine value (139), acid value (3.6), refractive index at $25{ }^{\circ} \mathrm{C}(1.4820)$, specific gravity at $25 / 25^{\circ} \mathrm{C}$ and $30 / 30{ }^{\circ} \mathrm{C}(0.9333 \& 0.925)$ viscosity at $25^{\circ} \mathrm{C}$ and $30{ }^{\circ} \mathrm{C}$ (200 cps \& 1.85 poise), respectively. Fatty acid composition was also determined to ascertain the extent of dehydration due to the formation of conjugated linoleic acid (CLA, 36.9\%) and non conjugated linoleic acid (NCLA, 46.8\%). Ricinoleic acid was estimated as 3.83\%. Unbodied DCO-15 was in good conformance with the standard specification of ASTM and other values cited in the literature.
\end{abstract}

Keywords: castor beans oil, gas liquid chromatography, ricinoleic acid, linoleic acid, dehydrated caster oil

\section{Introduction}

Castor beans Ricinus communis L., is a rich source of industrial oil crop, which is an important industrial oil crop of the world. Castor bean is successfully cultivated in tropical and sub tropical regions of Pakistan. Castor seeds contains about $50-55 \%$ of castor oil which is composed of $81-96 \%$ of glycerides of ricinoleic acid $\left(\mathrm{C}_{18} \mathrm{H}_{34} \mathrm{O}_{3}\right)$ (Castor-PARC). Ricinoleic acid (85-95\%) is reported as the predominant hydroxyl fatty acids of castor oil (Raie, 2008). This hydroxyl fatty acid makes the castor oil unique vegetable oil. Dehydrated castor oil is one of these derivatives and is employed in manufacture of paint and varnish and to improve the quality of house paints, enamels, caulks, sealants and inks.

In the process of dehydration, two isomers of linoleic acids were obtained according to the position of double bond, named as 9,12-octadecadienoic acid and 9,11octadecadienoic acid. On the basis of viscosity and iodine value dehydrated castor oil is categorised in two main types, termed as unbodied and bodied. Unbodied refers to the dehydrated castor oil (DCO) that has not been additionally heat polymerised. Bodied refers to polymerised castor oil of higher viscosity (7-100 poise) as mentioned by Krik-Othmer (1993). The aim of this

*Author for correspondence; E-mail: rba_saleem@hotmail.com study was to investigate the most suitable reaction conditions including minimum temperature and holding time at which the polymerisation of the oil has to be maintained to produce unbodied DCO of the standard specifications (ASTM, 1995, D961-86). Present work was based on the physicochemical characterisation of castor oil, utilisation of minimum quantity of chemicals to produce unbodied DCO and its physicochemical evaluation by applying standard analytical techniques at laboratory scale. This work was initiated first time in Pakistan.

\section{Materials and Methods}

Pure castor oil was procured from a super market in Saddar, Karachi, Pakistan. All chemicals including sodium bisulphate and sodium bisulphite, iodine monochloride, carbon tetrachloride, anhydrous sodium sulphate, sodium hydroxide, ethanol, methanol etc., pure standards of methyl esters of fatty acids were purchased from Merck, Sigma and Aldrich Co. Perkin Elmer's gas chromatograph, Clarus 500 model equipped with flame ionisation detector was used for fatty acid composition of castor and dehydrated castor oil. Rtx 2330 column was installed in GC oven. Dehydration reaction assemblies (three) were designated with respect to the excess time given to each system after $2.5 \mathrm{~h}$, as DCO-15, DCO-25, and DCO-35. 
Physicochemical analysis of refined castor oil. Acid value, iodine value, refractive index, specific gravity, viscosity and hydroxyl value of castor oil were determined by and ASTM and AOCS test methods (ASTM, 2006; AOCS, 1998).

Fatty acid composition of castor oil. Gas chromatographic analysis was conducted to evaluate fatty acids composition of castor oil. For this purpose fatty acid methyl esters were prepared according to the IUPAC method (IUPAC, 1987) and the GC conditions applied were same as in our previous work (Saleem et al.,2007).

Dehydration of castor oil. Castor oil $(0.250 \mathrm{~kg})$ was measured into three different round bottom flasks marked as DCO-15, DCO-25, DCO-35, equipped with thermometer, condenser, and mechanical stirrer. Sodium bisulphate $(1.3 \%)$ as catalyst and sodium bisulphite $(0.3 \%)$ as an antipolymerising agent were added into each flask. Reaction was initiated under vacuum 23-25"Hg to pull off water into the receiver. These systems were heated on three heating mantles with continuous stirring. Temperature of heating mantles was raised gradually from ambient to $230{ }^{\circ} \mathrm{C}$ within $2.5 \mathrm{~h}$ (150 min). Then DCO-15, DCO-25, DCO-35 were subsequently controlled at the same temperature for 15, 25 and $35 \mathrm{~min}$, respectively. Then reaction flasks were disconnected and cooled immediately and all the three products of DCO were filtered and weighed to calculate their yields.

Physicochemical analysis of unbodied dehydrated castor oil. DCO-15, DCO-25 and DCO-35 were analysed for acid value, hydroxyl value, refractive index, viscosity and specific gravity by using standard and ASTM and AOCS test methods (ASTM, 2006; AOCS, 1998). Iodine value was determined by using ISO (1996), this method is especially recommended for oils containing conjugated fatty acids such as tung oil and DCO.

Fatty acid composition of unbodied DCO. Gas chromatographic analysis was conducted to evaluate fatty acid composition of DCO and to assess the degree of dehydration by quantification of conjugated and non conjugated linoleic acid (CLA and NCLA) and ricinoleic acid. For this purpose fatty acid methyl esters were prepared according to the IUPAC method (IUPAC, 1987) and GC conditions applied were same as in our previous work (Saleem, et al., 2010).

\section{Results and Discussion}

Physicochemical analysis and fatty acid composition of refined castor oil. Physicochemical properties and fatty acid composition of castor oil are presented in Table 1. Acid value (0.5) proved that castor oil contained minimum amount of acidity in the form of free fatty acids and the oil is of good quality. Similarly, refractive index (1.4772), viscosity (6.8), hydroxyl value (162), iodine value (85) and fatty acid composition in Table 1, show that castor oil is pure and comply with the standard specification of castor oil . The oil was found to possess much potential to produce dehydrated castor oil due to the presence of ricinoleic acid (84\%) (Fig. 1).

Dehydration of castor oil. In three systems it was observed that water formation was initiated at $210-220{ }^{\circ} \mathrm{C}$ and transferred into the receivers at $230{ }^{\circ} \mathrm{C}$. It was evident from experimental results that DCO-15, 25 and 35 were quantitatively obtained as $93 \%, 80 \%$ and $75 \%$, respec-

Table 1. Physicochemical characteristics and fatty acid composition of castor oil

\begin{tabular}{lll}
\hline \hline Characteristics & $\begin{array}{l}\text { Current } \\
\text { values }\end{array}$ & Specification $^{\mathrm{a}}$ \\
\hline Specific gravity @ $25 / 25^{\circ} \mathrm{C}$ & 0.959 & $0.957-0.961$ \\
Viscosity @ $25{ }^{\circ} \mathrm{C}(\mathrm{St})=$ poise & 6.8 & $6.3-8.8$ \\
Acid value & 0.5 & 2.0 max \\
Refractive index @ $25^{\circ} \mathrm{C}$ & 1.4769 & 1.4764 or 1.4772 \\
Hydroxyl value & 162 & $160-168$ \\
Iodine value & 85 & $84-88$ \\
Fatty acid composition $(\mathrm{wt} \%)$ & - & - \\
Palmitic acid $\left(\mathrm{C}_{16: 0}\right)$ & 1.7 & 1.0 \\
Stearic acid $\left(\mathrm{C}_{18: 0}\right)$ & 1.39 & 1.0 \\
Oleic acid $\left(\mathrm{C}_{18: 1}\right)$ & 5.73 & 3.0 \\
Linoleic acid $\left(\mathrm{C}_{18: 2}\right) \mathrm{NCLA} *$ & 6.25 & 4.2 \\
Ricinoleic acid $\left(\mathrm{C}_{18: 1} \mathrm{OH}\right)$ & 84.2 & 89.5 \\
\hline \hline
\end{tabular}

${ }^{\mathrm{a}}=$ reference from Krik-Othmer (1993).

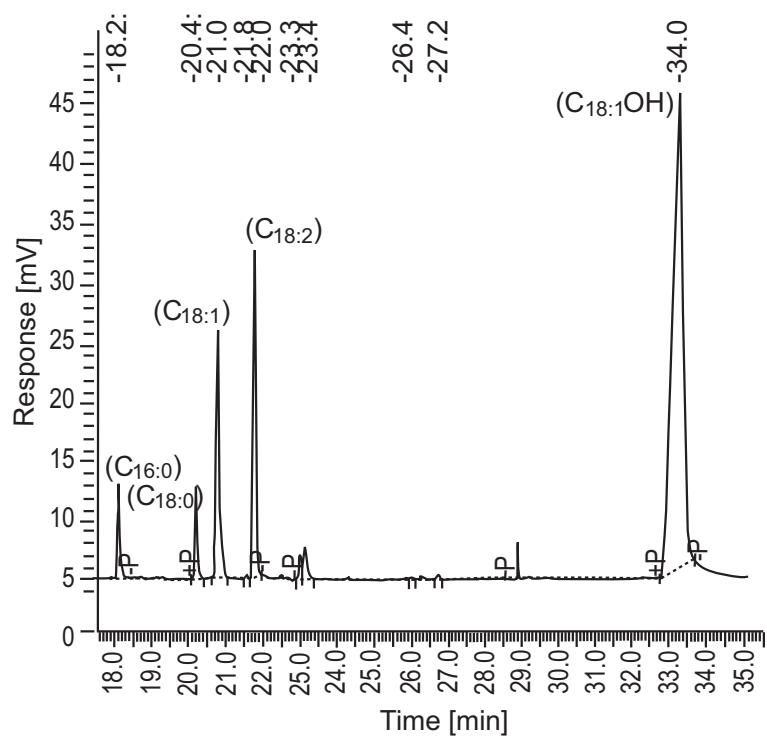

Fig. 1. Gas chromatogram of castor oil. 
tively, concluding that the minimum duration to produce the unbodied DCO in maximum amount was $165 \mathrm{~min}$ as in the case of DCO-15.

Physicochemical analysis of unbodied dehydrated castor oil. Specific gravity, viscosity, refractive index, iodine value. Specific gravity and viscosity are inversely proportional to temperature. In Table 2, it is mentioned that specific gravity $(0.9333,0.9346,0.937)$ and viscosity $(200,215,220 \mathrm{cps})$ at $25^{\circ} \mathrm{C}$ were higher than at $30^{\circ} \mathrm{C}$ $(0.925,0.928,0.932)$ and $(185,200,210 \mathrm{cps})$ of DCO- 15 , 25 and 35 , respectively. It was also evident from Table 2 that specific gravity and viscosity of sample DCO-15 were lower than DCO-25 and DCO-35.

As soon as the hydroxyl group and hydrogen were removed as water then viscosities were decreased, iodine value and refractive index were increased as compared to the pure castor oil. These parameters were used to

Table 2. Physicochemical characteristics and fatty acid composition of unbodied dehydrated castor oil

\begin{tabular}{|c|c|c|c|c|}
\hline \multirow[t]{2}{*}{ Characteristics } & \multicolumn{3}{|c|}{ Current values } & \multirow[b]{2}{*}{$\begin{array}{l}\text { ASTM D445 } \\
(2006)\end{array}$} \\
\hline & DCO-15 & DCO-25 & DCO-35 & \\
\hline $\begin{array}{l}\text { Specific gravity } \\
\text { (a) } 25 / 25^{\circ} \mathrm{C}\end{array}$ & 0.9333 & 0.9346 & 0.9370 & $0.926-0.937$ \\
\hline $\begin{array}{l}\text { Specific gravity } \\
\text { (a) } 30 / 30{ }^{\circ} \mathrm{C}\end{array}$ & 0.925 & 0.928 & 0.932 & - \\
\hline $\begin{array}{l}\text { Viscosity } \\
\text { (a) } 25^{\circ} \mathrm{C} \\
(\mathrm{cSt})=\mathrm{cps}\end{array}$ & 200 & 215 & 220 & $140-225$ \\
\hline Viscosity@ & $1.85=$ & $2.0=$ & $2.10=$ & - \\
\hline $30{ }^{\circ} \mathrm{C}$ (poise) & $185 \mathrm{cps}$ & $200 \mathrm{cps}$ & $210 \mathrm{cps}$ & \\
\hline Acid value & 3.6 & 6.8 & 7.9 & $6 \max$ \\
\hline $\begin{array}{l}\text { Refractive index } \\
\text { (a) } 25^{\circ} \mathrm{C}\end{array}$ & 1.4820 & 1.4813 & 1.4809 & $1.4805-1.4825$ \\
\hline Hydroxyl value & 12.4 & 14.8 & 16.9 & - \\
\hline $\begin{array}{l}\text { iodine value } \\
\text { Fatty acid }\end{array}$ & 139 & 120 & 115 & $125-145$ \\
\hline $\begin{array}{l}\text { composition } \\
(\mathrm{wt} \%)\end{array}$ & - & - & - & $* * *$ \\
\hline $\begin{array}{l}\text { Palmitic acid } \\
\left(\mathrm{C}_{16: 0}\right)\end{array}$ & 1.74 & 1.9 & 2.37 & $\begin{array}{l}0.5 \text { (total } \\
\text { saturated } \\
\text { fatty acids\} }\end{array}$ \\
\hline $\begin{array}{l}\text { Stearic acid } \\
\left(\mathrm{C}_{18: 0}\right)\end{array}$ & 1.58 & 1.42 & 2.79 & \\
\hline $\begin{array}{l}\text { Oleic acid } \\
\left(\mathrm{C}_{18: 1}\right)\end{array}$ & 5.58 & 5.94 & 6.68 & 7.5 \\
\hline $\begin{array}{l}\text { Linoleic acid } \\
\left(\mathrm{C}_{18: 2}\right)\end{array}$ & $46.8 / 36.98$ & $47.62 / 37.6$ & $44.99 /$ & $65 / 22$ \\
\hline $\begin{array}{l}\text { NCLA*/ } \\
\text { CLA** }\end{array}$ & 8 & 6 & 27.4 & \\
\hline $\begin{array}{l}\text { Ricinoleic acid } \\
\left(\mathrm{C}_{18: 1} \mathrm{OH}\right)\end{array}$ & 3.83 & 3.92 & 7.1 & 5.0 \\
\hline
\end{tabular}

monitor degree of dehydration and polymerisation. Iodine value of DCO-15 was higher (139) than the values for DCO-25 (120) and DCO-35(115). Iodine value of DCO 15 was maximum after a certain reaction time then decreased to a minimum (DCO-35,115) as the dehydration time was increased. Same conditions were observed by Naughton (1974), they reported that maximum iodine value was achieved near the minimum viscosity, beyond this point iodine value drops due to polymerisation.

Acid value and hydroxyl value. DCO-15 was found to possess the least acid value (3.6) as compared to the other two DCO-25 (6.8) and DCO-35 (7.9). This observation indicated that acid value was increased with time and higher than the prescribed limits of unbodied DCO. Similarly, hydroxyl value of three samples were also decreased from initial value i.e., 162 to $12.4,14.8$ and 16.9, respectively (Table 2), which is the indication that the dehydration process had been carried out and comparatively better quality unbodied DCO (DCO-15) was prepared than DCO-25 and DCO-35.

Fatty acid composition of unbodied DCO. Gas chromotographic (GLC) analysis of mono,di and polyunsaturated fatty acids of natural fats have been reported (Jabeen et al., 2013; Sultana, et al., 2011; Saleem, et al., 2008; 2007). Fatty acid composition of three products have been mentioned in Table 2. Figure 2 shows the gas chromatogram. Initially $6.25 \%$ of NCLA was present in castor oil. Due to dehydration process major part of ricinoleic acid was converted into NCLA and CLA. In DCO-15, 25 and 35, NCLA and CLA were quantified as $46.38 \%$ and $36.98 \%, 47.62 \%$ and $37.6 \%, 44.99 \%$ and $27.4 \%$, respectively. Ricinoleic acid was quantified as $3.83 \%, 3.92 \%$ and $7.17 \%$, respectively. These results

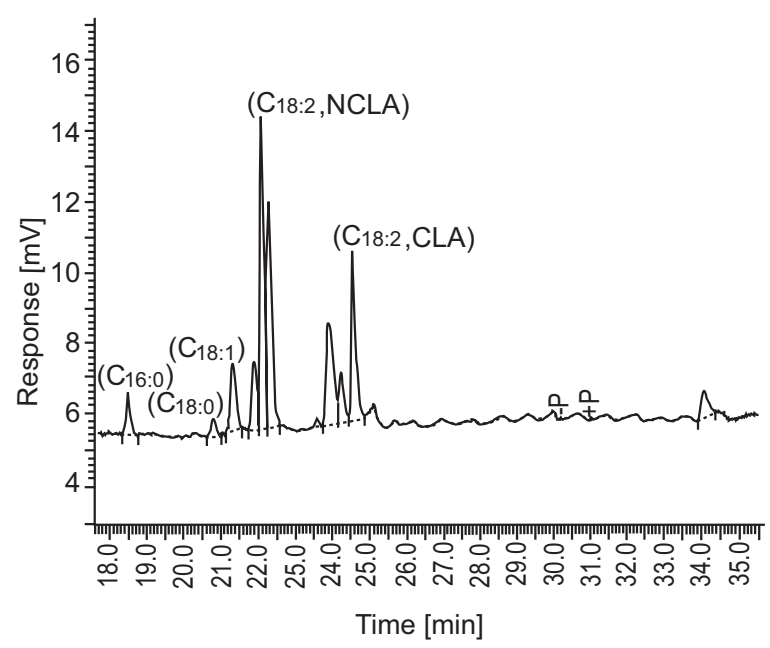

Fig. 2. Gas chromatogram of unbodied DCO. 
conclude that DCO-15 comply with unbodied DCO. In a previous study gas chromatographic analysis of dehydrated product showed $44 \%$ of total NCLA and 35\% CLA (Achaya, 1971).

\section{Conclusion}

Unbodied DCO of minimum viscosity and maximum iodine value was obtained by heatings the reaction mixture at $230{ }^{\circ} \mathrm{C}$ further maintained for $15 \mathrm{~min}$ (DCO15). This product was found to possess a low quantity of ricinoleic acid (RA) due to the conversion of major part of RA into NCLA and CLA. The other two products, DCO-25 and DCO-35, obtained by maintaining the temperature for further 25 and $35 \mathrm{~min}$, respectively, were also dehydrated castor oil but their viscosities were comparatively higher and iodine value was lower than DCO-15.These products were categorised as bodied DCO. It was concluded from this study that total appropriate time for dehydration was $165 \mathrm{~min}$ to prepare a good quality unbodied DCO (DCO-15).

\section{References}

Achaya, K.T. 1971. Chemical derivatives castor oil . Journal of the American Oil Chemists Society, 48:758-763.

AOCS, 1998. Official Methods and Recomended Practices of the American Oil Chemist's Society, $5^{\text {th }}$ edition, Methods Cd 3d-63, Cd 1-25, Ce 7-25, Ce 10a-25 and Cd 13-60, AOCS Press, Compaign, Illinoise, USA.

ASTM, 2006. Standard Test Method for Kinematic Viscosity of Transparent and Opaque Liquids and the Calcula-tion Dynamic Viscositi, D4456., American Society for Testing and Materials International, 100 Barr Harbor Drive, West Conshohoken, PA., USA.

ASTM, 1995. Standard Specification for Dehydrated Castor Oil, D961-86, American Society for Testing and Materials International, 100 Bar Harbor Drive, West Conshohoken, PA., USA.

Baily, A.E. 1964. Bailey's Industrial Oil and Fat Products, D. Swern (ed.), Interscience Publkishers, Michigan, old.parc.gov.pk/1SubDivision/NARCCSI/CSI/ oil.html, USA.

Castor-PARC. Pakistan Agricultural Research Council http//www.parc.gov.pk.
ISO, 1996. Animal and Vegetable Fats and Oils, Determination of Iodine Value, ISO-1996 (E) 3961, International Organisation for Standardisation, Geneva, Switzerland.

IUPAC, 1987. Standard Methods 2-301, Preparation of Fatty Acid Methyl Esters in Standard Methods for the Analysis of Oils, Fats and Derivative, C. Paquot and A. Hauufenne (eds.), $7^{\text {th }}$ edition, International Union of Pure and Applied Chemostry, Blackwell Scientific Publication, London, UK.

Jabeen, N., Ahmed, R., Sultana, R., Saleem, R., Ambrat, 2013. Investigations on foliar spray of boron and manganese on oil content and concentration of fatty acids in seeds of sunflower plant raised through saline water irrigation. Journal of Plant Nutrition, 36: 1001-1011.

Krik-Othmer, 1993. Krik-Othmer Encyclopaedia of Chemical Technology, J. Kroschwitz (ed.), vol. 5, pp. 302, 308, 529, $4^{\text {th }}$ edition, John Wily \& Sons, New York, USA.

Naughton, F.C. 1974. Production, chemistrty, and commercial application of various chemicals from castor oil. Journal of American of Oil Chemists Society, 51: 65-71.

Raie, Y.M. 2008. Oil, Fats and Waxes, 91 pp., Chapter $5,1^{\text {st }}$ edition, National Book Foundation, Islamabad, Pakistan.

Saleem,R., Sultana, R., Ambrat. 2010.Quality evalua-tion and fatty acid composition of palm oil cultivated in two regions of Pakistan. Pakistan Journal of Scientific and Industrial Research, 53: 239-245.

Saleem, R., Ambrat., Yaqeen, Z., Sohail,T. 2008. Quantitation of fatty acids by GLC and separation of omega 6 neutraceutical fatty acids from Carthamus tinctorius seed oil cultivated in Pakistan. Pakistan Journal of Scientific and Industrial Research, 51: 136-139.

Saleem,R., Sultana, R., Ambrat and Askari, B. 2007. Proximate analysis and fatty acid composition of Nigella sativa (Kalonji) seed oil growing in Pakistan. Pakistan Journal of Scientific and Industrial Research. 50: 308-312.

Sultana R., Saleem, R., Ambrat. 2011. Effect of temperature on the fatty acid composition and physicochemical characterization of oil extracted from Pakistani origin Carthamus tinctorius Thori-78 seeds roasted at different temperature. Pakistan Journal of Scientific and Industrial Research, 54: 26-32. 